\title{
A experiência internacional de regimes de metas de inflação: uma análise com painel dinâmico
}

\author{
Marcos Rocha \\ Mestrando em Desenvolvimento Econômico \\ da Universidade Federal do Paraná \\ José Luis Oreiro \\ Professor da Universidade Federal do Paraná \\ e pesquisador do $\mathrm{CNPq}$
}

\begin{abstract}
Palauras-chave
painéis dinâmicos, metas de inflação, política monetária.
\end{abstract}

Classificação JEL C23, F31, F33.

Key words

dynamic panels, inflation targeting, monetary policies.

JEL Classification C23, F31, F33.

\section{Resumo}

Este paper usa um modelo de crescimento com painel dinâmico para investigar como (e se) a arquitetura institucional dos regimes de metas de inflação afeta a performance de crescimento dos países adeptos. Foram selecionados 23 países que adotam oficialmente o regime de metas de inflação para compor a amostra do painel, que usa a metodologia de Arellano e Bond (1991) para estimar uma função de crescimento dinâmica. Os resultados apóiam a hipótese de que a adoção do IPC cheio para guiar a busca das metas - na medida em que é um índice de maior credibilidade -, a utilização de um horizonte de convergência para as metas maior do que o de um ano, e a capacidade de os Bancos Centrais evitarem desvios das metas são fatores benéficos de importância para a trajetória de crescimento do produto.

\section{Abstract}

This paper uses a growth model with dynamic panel techniques in order to investigate how (and if) the institutional architecture of inflation targeting regimes affects the growth performance of the countries that adopt this kind of monetary policy. The sample used to build the panel consists of 23 countries that officially adopted the inflation targeting regime. The Arellano and Bond (1991) methodology is used to estimate the parameters of the dynamic growth model. The results support the view that the adoption of headline inflation indices, since it is a index of strong credibility; the definition of a convergence horizon for target inflation larger than a year; and the capability of central banks to achieve the target inflation have positive and important effects over growth performance of selected countries. 


\section{1_Introdução}

Há um consenso geral entre a maior parte dos economistas de que uma taxa de inflação baixa e estável é um fator importante para a saúde de uma economia. Também ficou cristalizado na literatura econômica que a política monetária é um dos instrumentos mais flexíveis e poderosos para se atingir objetivos de médio prazo com relação a diversos indicadores da dinâmica macroeconômica de um país. Nos anos 1950 e 1960, predominou a visão de que a política monetária deveria ser "ativa", no sentido de que a discricionariedade dos policy-makers deveria ser posta em ação para garantir o assim chamado "nível de pleno emprego" da economia. Aqueles que postulavam o ativismo monetário se amparavam numa relação de longo prazo entre inflação e desemprego que formalmente é estabelecida pela curva de Phillips nos livros-texto. Muitos então acreditavam na possibilidade de "explorar" indefinidamente essa relação de forma a manter o nível de desemprego baixo.

Essas idéias foram fortemente abaladas por duas frentes: uma delas foi a experiência de crescentes taxas de inflação que as economias desenvolvidas vinham experimentando, concomitantemente a agudas taxas de desemprego; aparentemente, a relação estabelecida pela curva de Phillips tinha deixado de funcionar. Além disso, novas visões a respeito da relação inflaçãoproduto no longo prazo despontavam na teoria econômica: Friedman (1968) já havia estabelecido uma bem convincente crítica à discricionariedade dos policy-makers na condução da política monetária; ele apontava não só que os dirigentes não eram bons condutores do agregado monetário, mas também que sua condução deixava de ter impactos no emprego de longo prazo. Mais adequado, para Friedman, era a adoção de uma regra fixa clara: o Banco Central deveria perseguir uma meta de crescimento constante para a oferta de moeda. A adoção das idéias monetaristas que tiveram seu germe na argumentação Friedmaniana se deu no fim dos anos 1970 com uma série de programas monetaristas "apertados". Alguns desses programas entraram em voga na pauta das prescrições de política econômica às economias subdesenvolvidas no término dos anos 1980 - que se viam então presas a uma avalanche de débito internacional e patologia inflacionária - como condição a inserção nas finanças internacionais.

Uma vasta literatura se seguiu a controvérsia convencional entre discricionariedade e regra fixa que teve palco na década de 1970. Inúmeras também foram as variantes de políticas sugeridas, mais ou menos focadas em um ou outro pólo da discussão 
sobre regra e decisão na condução da moeda. Atualmente, prevalece a noção de que uma política monetária de sucesso deve ser disciplinada - em especial para os países em desenvolvimento, tidos como "indisciplinados" por natureza - e transparente. A transparência das metas monetárias e dos meios utilizados para atingi-las é implementada com um cuidado em demonstrar compromisso rígido de austeridade, comportamento seguido pelos Bancos Centrais em geral devido ao problema notadamente conhecido como inconsistência temporal. ${ }^{1}$

A disciplina e a transparência requeridas sugerem alguma espécie de âncora nominal para a política monetária. Nos anos 1990, um número crescente de países implementou o inflation targeting-doravante IT - um regime de metas inflacionárias. A dis- seminação se deu em parte em razão do fracasso de outras estratégias de âncoras nominais, como metas de taxas de câmbio ou metas monetárias dirigidas por Bancos Centrais. No caso de metas monetárias, os problemas surgiram fundamentados no seguinte ponto: embora o Banco Central possa controlar diretamente a base monetária ou tentar controlar algum agregado monetário, a relação dessa política com a inflação efetiva é muitas vezes tênue, o que torna ineficaz o papel da meta com relação à modelagem das expectativas inflacionárias dos agentes. ${ }^{2}$

Parece haver convergência dentro do pensamento econômico mainstream contemporâneo de que o regime de IT é uma boa via de amparo para a política monetária garantir baixas taxas de inflação. ${ }^{3}$ Segundo Bernanke et al. (1999), a transparência e a flexi-
1 Há extensa literatura tratando do problema da inconsistência temporal, boa parte derivada do trabalho de Kydland e Prescott (1977). Os autores mostram que a inabilidade da autoridade monetária em se comprometer a uma política de baixa inflação pode levar à inflação excessiva, mesmo na existência de ausência de trade-off de longo prazo entre produto e inflação de longo prazo. Se a inflação esperada for baixa e, portanto, o custo marginal social de aumentar a inflação for baixo, os policy-makers vão perseguir políticas expansionistas como forma de elevar temporariamente o produto acima de seu nível normal de equilíbrio (imperfeições de mercado e outros fatores poderiam fazer com que o produto potencial seja menor do que o socialmente desejável, o que justificaria tal motivação). O conhecimento geral desse incentivo dos policy-makers, ou a existência de tal possibilidade por parte dos Bancos Centrais quando não há comprometimento com baixa inflação, faz com que os agentes elevem suas expectativas inflacionárias; isto é, o inflation bias derivado da inconsistência intertemporal ou dinâmica. No fim, a política discricionária resulta apenas em mais inflação, e nenhum acréscimo no produto.

2 Segundo Carlin e Soskice (2006), na Grã-Bretanha era comum que, sempre que a autoridade monetária tentava controlar um agregado monetário em particular como meta, havia uma resposta seqüencial do sistema financeiro na forma da emergência de substitutos próximos ou "quase-moedas" que se assentavam aquém da meta estabelecida e, assim, subvertia-a. Mudanças na demanda por moeda (instabilidade da velocidade monetária) minam a conexão entre a meta de crescimento monetário e a inflação, fazendo ineficiente a política do monetary targeting; esses problemas determinaram o fim da prática de tal regime nos EUA, no Canadá e na Grã-Bretanha.

3 Sobre esse consenso, conferir Woodford (2003). 
bilidade associadas aos regimes IT são suas maiores virtudes. A transparência consiste na clara comunicação dos Bancos Centrais e o público a respeito dos rumos de seus objetivos políticos, do que sua política monetária pode e do que não pode fazer, reduzindo beneficamente a incerteza inerente ao ambiente econômico com que se defrontam os agentes econômicos. A flexibilidade consiste na competência que nesses regimes os Bancos Centrais têm para reagir efetivamente a choques macroeconômicos de curto prazo dentro dos limites que o próprio regime estabelece de forma bastante clara. Entretanto, no dia-a-dia, escolhas de natureza operacionais que promovam a transparência podem reduzir a flexibilidade da autoridade monetária, e vice-versa. Nas palavras dos autores,

Thus, in the design of an inflation-targeting strategy, often a key issue is the proper balancing of transparency and flexibility (Bernanke et al., 1999).

Portanto, a maneira pela qual o Banco Central implementa sua estratégia de IT tem impacto significativo no balanço entre transparência e flexibilidade, um trade-off com que a autoridade monetária se defronta permanentemente. Daí advém a conclusão de que - e esta parece ser a posição dos autores - uma vez resolvido pelo Banco Central como esse designará ope- racionalmente sua política de metas de inflação, a persecução de baixas taxas de inflação é amparada da melhor forma por esse regime.

A literatura a respeito do sucesso dos regimes IT em efetivamente combater a inflação, entretanto, é ainda bastante controversa. ${ }^{4}$ Mas um aspecto importante da discussão merece atenção, tanto quanto aquela dedicada à observação do sucesso dos países que adotam IT no controle de seus preços: esse aspecto é a performance do produto desses países e os custos associados a processos de desinflação, convergência e manutenção de baixas taxas de inflação. Há espaço para discutir se o Banco Central deve se preocupar com os custos sociais em termos da volatilidade de juros, câmbio e, mais importante, de produto e emprego, ao estabelecer a forma como instrumentaliza a convergência das taxas de inflação às metas? Há uma maneira ótima de estruturar institucionalmente a IT? Como a experiência internacional oferece subsídio para discernir, entre os diversos desenhos de adoção de IT, aquele que mais sucesso deriva na performance de crescimento e desenvolvimento de uma economia que afinal é, ou deveria ser, o fim último da procura pela estabilidade de preços? Não há uma resposta fácil para essas questões, evidentemente; este trabalho é uma incipi- $\cdots \ldots \ldots \ldots$ 4 O trabalho de Wu (2004) mostra que a adoção das metas explica parte significativa da redução da inflação desses países. Entretanto, Cecchetti e Hermann (2000), Sicsu (2002), Ball e Sheridan (2003), entre outros, apontam que o regime de metas não pode solidamente ser associado com os resultados de baixa inflação ou que não há evidências para tal afirmativa. Há evidências de que forças que já estavam em ação foram responsáveis pela redução das taxas de inflação da Nova Zelândia,

do Canadá e do Reino Unido; além disso, Canadá e Reino Unido também viviam um contexto de desaquecimento econômico quando adotaram o IT (Mishkin e Posen, 1997). 
ente busca de dar alguma luz para o que algum dia venha ser uma resposta definitiva a essas importantes preocupações.

Como será detalhado neste paper, a adoção de um regime de IT como forma de guiar a política monetária em um país pode ter vários desenhos: sua formatação institucional é crucial para garantir a obtenção das metas e a construção da credibilidade. No momento em que o IT é utilizado, os policy-makers têm uma ampla opção de escolha no sentido de estabelecer a forma institucional pela qual o regime vai operar: se amparado em índices de core inflation ou beadline inflation, se estabelecendo um ponto numérico de convergência para a taxa de inflação ou bandas de intervalo de diversas amplitudes, se anunciando um horizonte temporal de um ano ou um prazo maior pelo qual se espera que a inflação tenha convergência à meta estabelecida, etc. Cada uma das escolhas pode dar ao regime um caráter institucional monetário específico: ele pode ser mais "apertado", no sentido de que é estruturado com forte ênfase ao sucesso das metas estabelecidas em detrimento a qualquer custo de operacionalização dessa convergência; ou pode ser mais "flexível”, situação em que o arranjo do IT se faz com tendência a levar-se em consideração os custos e o horizonte temporal exigido para o cumprimento das metas. Estes pó- los - regime apertado ou flexível - estão fortemente associados, de um lado, à credibilidade, que é ponto fundamental para os regimes IT apertados ou em consolidação e, por isso mesmo, são mais comumente adotados por países em busca de uma trajetória de inflação decrescente; e, do outro, à preocupação com a extrema volatilidade de juros, câmbio e produto associados a um regime IT apertado, o que explica por que a maioria dos países que já têm seu regime IT consolidado ou o adotaram em contexto apenas de manutenção de baixas taxas de inflação utilizam um arcabouço institucional de operação mais "flexível", ou passam a utilizá-lo uma vez que os objetivos das autoridades monetárias vão se consolidando com relação às expectativas do público. Nas seções subseqüentes, ficarão mais claros quais são os arranjos institucionais que caracterizam a experiência internacional dos regimes de IT e qual o significado de "aperto" ou "flexibilização" do IT, além de suas conseqüências com relação às performances dos regimes nos países.

O objetivo deste artigo é, além de esclarecer como opera o arcabouço institucional para os resultados experimentados com adoção de metas inflacionárias, investigar como o tal arranjo impacta sobre a performance de crescimento dos países que adotaram o IT. A fundamentação teórica 
para este estudo se encontra na teoria Keynesiana, notadamente na análise do circuito de finance e funding das decisões de investimento em capital fixo; haja vista que os modelos neoclássicos de crescimento são, em sua larga maioria, modelos de crescimento sem moeda. ${ }^{5}$ Como fica claro adiante na seção 3 deste artigo, um arcabouço institucional para a condução da política monetária que dê mais graus de liberdade ao Banco Central na operação dessa política pode contribuir positivamente para o crescimento de longo prazo, à medida que permite melhor atendimento dos requerimentos de liquidez para o crescimento, ajudando assim a estabilizar a taxa de juros de longo prazo da economia.

Assim, a preocupação está em qualificar as medidas que podem garantir aos países a estabilidade macroeconômica em sentido mais amplo - mais do que a estabilidade de preços, a manutenção do crescimento econômico. Para isso, é feito um exercício com dados em painel dinâmico que incorpora variáveis de caráter monetário institucional numa função de produção típica da literatura empírica de crescimento como forma de discutir o papel potencial do formato institucional do IT sobre as taxas de crescimento dos países.

Seguindo esta introdução, a seção 2 detalha o funcionamento dos regimes de IT e apresenta algumas evidências da experiência internacional. A seção 3 pormenoriza a fundamentação teórica que deu origem à especificação funcional do painel dinâmico utilizado para o exercício econométrico. A seção 4 explora os resultados empíricos obtidos. A seção 5 encerra o trabalho com algumas considerações finais.

\section{0 arranjo institucional dos regimes de metas de inflação}

Esta seção detalha alguns aspectos operacionais associados aos ITs que emergem quando da adoção do regime por um país. O framework do IT deve ser desenhado de forma que a condução da política monetária seja orientada consistentemente na direção da obtenção das metas; ao mesmo tempo, entretanto, devem ser levados em consideração os limites para tal tarefa. A inflação não está totalmente sobre o controle dos Bancos Centrais, e esses se defrontam com o custo social, em termos de produto, de algumas políticas. A seguir ficará mais claro como o desenho institucional apresenta trade-offs aos Bancos Centrais, que, nas suas escolhas, determinarão o grau de austeridade do seu regime IT.

O horizonte temporal das ITs. O horizonte temporal é o período durante o qual

\footnotetext{
A esse respeito, ver

Davidson (1994, cap. 8).
} 
se espera que os instrumentos da política monetária ajustem a inflação à sua meta. A inflação não retorna imediatamente à sua meta porque existem fricções na economia (como contratos salariais, entre outras rigidezes) que fazem com que a inflação persista. Além disso, a política monetária age com defasagens de tempo, como Friedman (1968) apontou enfaticamente ao sugerir precauções no uso de tal instrumento (ou nenhum uso). Como nesse regime há o interesse de ancorar as expectativas inflacionárias dos agentes econômicos, os policymakers buscam o máximo de transparência em suas políticas, comunicando ao público o horizonte de tempo planejado. A escolha do horizonte apropriado envolve um balanço entre os custos de volatilidade de gap de produto e a taxa de juros contra os benefícios de se manter a taxa de inflação dentro da meta estabelecida. Como aponta Coletti et al. (2006), a duração do horizonte temporal ótimo para atingir a meta varia amplamente, dependendo da intensidade e da natureza dos choques que sofrem a economia. Quando há um tal aceleramento de preços detonado por um choque persistente, como bolhas de ativos, por exemplo, pode ser necessária uma expansão do horizonte das metas de inflação, para acomodar de forma estável o potencial desestabilizador do choque.
Um horizonte temporal curto é associado a mudanças robustas nas taxas de juros, de forma a dirigir a inflação à sua meta rapidamente. A política monetária, como é amplamente reconhecido, afeta as variáveis da economia, particularmente a inflação, com defasagens que são tipicamente estimadas, segundo Mishkin (2001), em cerca de dois anos. Para o autor, horizontes de tempo menores, como o de um ano que tem sido a prática de alguns regimes de IT e é correntemente utilizado pelo Brasil - podem trazer três grandes problemas à condução do regime. Um horizonte tão pequeno tende a estar associado à freqüente perda da meta de inflação pelo Banco Central. O segundo problema relacionado ao horizonte curto é de que ele está associado a uma instabilidade instrumental: os instrumentos de política são demasiadamente postos em ação de modo a fazer com que a inflação atinja sua meta nesse horizonte de tempo estreito. O problema nesse caso é a excessiva volatilidade das taxas de juros e da economia em geral, uma vez que os efeitos defasados, resultado de mudanças bruscas nas taxas de juros, podem então ser corrigidos por subseqüentes desvios dos juros em direção oposta. Um terceiro problema apontado por Mishkin é o de que tal horizonte de convergência estreito implica que o Banco Central se apresente ao público como não dando devida 
ponderação às flutuações de produto em sua função de perda.

Um horizonte de tempo de convergência maior é consistente com uma mudança mais lenta nas taxas de juros que tendem a resultar em menor volatilidade real; entretanto, esse esquema pode fazer com que os desvios da inflação de sua meta estabelecida se tornem mais persistentes. Portanto, pode-se dizer que há um horizonte temporal ótimo para a convergência das metas que balanceia esses dois argumentos opostos. Cada tipo de choque à economia terá seu próprio horizonte ótimo para a IT, porque cada choque leva a um tradeoff diverso entre a volatilidade do produto e a da inflação.

Para determinar-se o horizonte ótimo da IT, é necessária uma medida quantitativa das perdas que sofre a economia derivadas das volatilidades no produto, inflação e taxas de juros necessárias na instrumentalização de uma política monetária muito rápida, e do grau de credibilidade perdido ao se estabelecer uma política de horizonte muito amplo. Em muitos modelos, os parâmetros das regras de política monetária que relaciona as mudanças na política dos juros a desvios previstos da inflação de sua meta e também levam em conta o estado corrente do gap de produto - são alterados para determinar o horizonte temporal que minimiza as perdas de uma economia. Esse exercício pode ser repetido para uma vasta gama de choques potenciais. Segundo Colleti et al. (2006), os resultados em geral defendem a tese de que diferentes choques são associados a diferentes horizontes temporais ótimos, indicando que o horizonte de IT ótimo varia da mesma forma que variam os choques potenciais da economia. $\mathrm{O}$ trabalho ainda sublinha que, nos casos em que uma aceleração dos preços é detonada por um choque grande e persistente, pode ser apropriado definir maior amplitude para o horizonte temporal do IT.

$A$ adoção de um ponto ou de uma banda. O Banco Central pode escolher entre definir uma meta pontual ou um intervalo ao redor de um ponto médio. A escolha de um intervalo, obviamente, coloca ao Banco Central um trade-off relacionado à amplitude da banda estabelecida. Uma banda mais estreita comunica ao público maior comprometimento do Banco Central em atingir a meta do que uma banda mais larga; a credibilidade está associada a bandas mais estreitas. O outro lado do trade-off é de que bandas muito estreitas reduzem consideravelmente a habilidade de a autoridade monetária responder a choques exógenos inesperados. Mais ainda, o estrago à imagem do Banco Central derivado da perda do cumprimento de uma banda de meta é 
consideravelmente maior do que aquele derivado da perda de uma meta pontual.

O valor numérico da meta de inflação. Dentro do arranjo instituído no regime IT, um ponto central para qualquer Banco Central é a escolha da meta de inflação de longo prazo. Para Mishkin (2001), considerações a respeito da meta de inflação de longo prazo apropriada necessitam que se defina de forma clara o que significa a estabilidade de preços, e cita a famosa definição de Greenspan de que a estabilidade de preços é aquela dada por uma taxa de inflação que é suficientemente baixa para que os agentes da economia não necessitem levar em conta a inflação para fazer suas decisões econômicas cotidianas. Diante dessa definição razoável, qualquer inflação entre 0 e 3 por cento pode atender ao critério para as economias desenvolvidas, embora alguns economistas como Feldstein (1997) e Poole (1999) apontem para uma inflação de longo prazo de 0 por cento, cuja virtude seria o apelo de um "número mágico" como zero às expectativas dos agentes. A experiência internacional, entretanto, como pode ser conferido em Bernanke et al. (1999), sugere que a manutenção da meta de inflação acima de zero (mas não muito), por um período extenso, não levou à instabilidade das expectativas do público ou a um declínio da credibilidade dos Bancos Centrais. Ademais, Akerlof et al. (1996) argumentam que definir a inflação a níveis tão baixos produz uma ineficiência que resulta em aumentos na taxa de desemprego natural. Eles apontam que a rigidez para baixo dos salários nominais faz com que a redução dos salários reais só possa ocorrer via inflação. A implicação de uma taxa de inflação tão baixa é a impossibilidade de os salários se ajustarem para baixo em resposta à demanda por trabalho declinante em algumas indústrias ou regiões, levando ao aumento do desemprego e dificultando a alocação de trabalho entre setores declinantes e aqueles em expansão.

Mishkin (2001), argumentando contra a hipótese de meta de inflação zero, diz que tal alvo faria com que a economia provavelmente experimentasse episódios de deflação que são potencialmente bastante perigosos, uma vez que promovem instabilidade financeira e podem fazer com que as decisões de política monetárias se tornem mais difíceis, se as taxas de juros de curto prazo baterem um piso zero como resultado. Assim, a lógica contra a meta de inflação zero é de que acertar uma taxa de inflação positiva provê segurança contra episódios deflacionários. Mishkin aponta ainda uma razão adicional para que os Bancos Centrais persigam uma inflação acima de zero: do contrário, eles podem ser percebidos pe- 
lo público como obcecados com o controle da inflação a expensas da igualmente necessária estabilidade do produto, perdendo o aval legitimador da sociedade.

A medida de inflação a ser usada. É um dos primeiros passos para o desenho do IT. Se o objetivo por parte da autoridade monetária é a busca de máxima transparência, o índice de preços, como sugerem Bernanke et al. (1999), deve ser aquele com que as pessoas já estão familiarizadas e que é amplo e acurado. Se a busca for flexibilidade, o índice deve excluir mudanças de preço que supostamente não afetem a tendência inflacionária ou a chamada core inflation, como aqueles preços associados a taxas de juros ou a movimentos de preços temporários e/ou de natureza apenas volátil.

A tendência atual tem sido a escolha de IPC cheios, sendo que apenas alguns países ainda utilizam um índice core em seus regimes; o Quadro 1 traz alguns exemplos de países que abandonaram o uso core inflation. A razão para isso pode ser que as autoridades monetárias não querem que o público tenha a impressão de que o Banco Central escolhe aquele índice que melhor se adapte a garantir resultados mais favoráveis, ou seja, a busca pela credibilidade com o uso do IPC cheio talvez tem sido mais crucial para as autoridades monetárias do que a flexibilidade oferecida pelo IPC core.

Quadro 1_A experiência internacional com índices "core" para metas inflacionárias

\begin{tabular}{|c|c|c|c|}
\hline Nunca utilizou core & Utiliza IPC Core & Exclui apenas os juros & Abandonou Core (2) \\
\hline Brasil (1999) & Canadá (1991) & África do Sul (2000) & Austrália (1993-1998) \\
\hline Chile $(1991)^{(1)}$ & Tailândia (2000) & Inglaterra (1992) & Nova Zelândia (1990-1999) \\
\hline Colômbia (1999) & & & República Tcheca (1998-2002) \\
\hline \multicolumn{4}{|l|}{ Islândia (2001) } \\
\hline \multicolumn{4}{|l|}{ Israel (1992) } \\
\hline \multicolumn{4}{|l|}{ México (1999) } \\
\hline \multicolumn{4}{|l|}{ Peru (1994) } \\
\hline \multicolumn{4}{|l|}{ Polônia (1998) } \\
\hline \multicolumn{4}{|l|}{ Suécia (1993) } \\
\hline Suíça (2000) & & & \\
\hline
\end{tabular}


Embora o IPC core seja menos volátil para a maioria dos países que usam IT (e, portanto, exigiriam menos dos Bancos Centrais o uso de seus instrumentos), em alguns ele foi desenhado de forma tal que pouco se diferenciava nas séries de tempo do IPC cheio, em termos de volatilidade (Ferreira e Petrassi, 2002).

No Brasil, o índice de core inflation não é utilizado para orientar as metas. Um dos motivos, como salientado em Minella et al. (2002), é que, em algumas ocasiões durante as décadas de 1970 e 1980, o governo excluiu alguns itens do índice beadline com fundamentações ad hoc como forma de apenas reduzir as taxas de inflação oficial - ou ainda agia mudando o cálculo do índice. O resultado é que o público no Brasil é bastante relutante em aceitar um índice que exclua alguns itens, em face dessas experiências passadas.

\section{Crescimento e não- neutralidade da moeda: fundamentos teóricos}

Esta seção busca justificar o arranjo da especificação econométrica utilizada no artigo como estratégia para entender como mudanças no arcabouço institucional do IT afetam a performance do produto real, fazendo uma breve discussão a respeito dos modelos de crescimento econômico.

Este trabalho se baseia na especificação empírica dos modelos neoclássicos de crescimento, mas estende essa de forma a incorporar variáveis que descrevem a adoção ou a mudança do arranjo institucional do regime de metas inflacionárias. $A$ intuição aqui é a de que determinados desenhos desse arranjo favorecem o crescimento econômico mais do que outros. Mais especificamente, a hipótese a ser testada é que arranjos institucionais do regime de IT que permitam maior grau de discricionariedade na condução da política monetária por parte do Banco Central tendem a favorecer o crescimento econômico de longo prazo.

Como é bem sabido, os modelos neoclássicos de crescimento, em geral, desconsideram qualquer vínculo causal entre as variáveis de cunho monetário e o crescimento do produto no longo prazo. A justificativa para a inclusão do arcabouço institucional no contexto dos modelos de crescimento de longo prazo é mais bem compreendida com uma argumentação baseada na hipótese de não-neutralidade da moeda no longo prazo, de inspiração tipicamente Keynesiana. Isso porque, nos modelos neoclássicos de crescimento sem moeda, o nível de equilíbrio de longo prazo da intensidade do capital e da taxa de retorno do capital é determinado pela tecnologia e pelas preferências intertemporais dos agentes econômicos, sendo assim independente da política monetária. 
A introdução da moeda nos modelos de crescimento neoclássico foi feita por Tobin (1965) e Sidrauski (1967). ${ }^{6}$ Nessa classe de modelos, considera-se a existência de dois ativos: moeda e capital. Dessa forma, os agentes econômicos podem poupar tanto por intermédio da compra de bens de capital (como nas versões não-monetárias do modelo neoclássico de crescimento) como por intermédio da acumulação de saldos monetários. Moeda e capital são considerados substitutos imperfeitos entre si, de tal maneira que, em equilíbrio, a taxa de retorno da moeda pode ser inferior à taxa de retorno do capital, em função dos serviços de conveniência que essa presta para os agentes econômicos. Nesse contexto, a moeda é um ativo que concorre com o capital pela preferência dos agentes econômicos como forma de acumulação de riqueza no tempo. Sendo assim, a existência de uma "preferência pela liquidez" vai fazer com que uma parte da poupança das famílias não esteja disponível para a aquisição de bens de capital, sendo destinada para a aquisição de saldos monetários, o que reduz a taxa de acumulação de capital.

No equilíbrio de steady-state do sistema, o estoque de capital por trabalhador e a taxa de retorno do capital passam a depender da taxa de crescimento da oferta de moeda. Isso porque um aumento da taxa de crescimento da oferta de moeda vai gerar um crescimento da taxa de inflação, aumentando assim o custo de oportunidade de retenção da moeda no portfólio das famílias. Isso, por sua vez, vai fazer com que os agentes econômicos reduzam a sua "preferência pela liquidez", substituindo moeda por capital em seus portfólios. Por fim, essa substituição vai induzir um aumento temporário do nível de investimento, um crescimento de forma permanente no estoque de capital por trabalhador e no produto por trabalhador da economia em consideração. Nesse contexto, observa-se que variações da taxa de crescimento da oferta de moeda têm efeito sobre as variáveis reais da economia no longo prazo.

Uma fundamentação alternativa à neoclássica e a de Tobin para a relação entre moeda e crescimento econômico foi feita por Davidson (1968). ${ }^{7}$

Most Keynesian growth models have (erroneously) ignored the monetary requirements for growth. Professor Tobin has, at least, attempted to show that monetary factors are of primary importance in growth. Unfortunately, he ties money supply requirements too closely to portfolio balances and not sufficiently to the requirement of finance where it belongs (Davidson, 1968, p. 319).

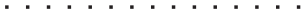

Uma exposição detalhada

da estrutura formal dos modelos neoclássicos de crescimento com moeda, para o leitor interessado, é encontrada em Walsh (2001, cap. 2).

7 Davidson não apresenta um modelo formal de crescimento para fundamentar as suas idéias a respeito da relação entre a condução da política monetária e o crescimento de longo prazo. Sua análise é puramente apreciativa, limitando-se a "demonstrar" a validade de alguns dos seus argumentos por intermédio de gráficos. 
8 Para um detalhamento dos conceitos de finance e funding, ver Carvalho et al. (2000, cap. 20).
A partir dessa crítica, o autor analisa o papel da política monetária no processo de finance e funding das decisões de investimento em capital fixo. ${ }^{8} \mathrm{O}$ ponto de partida de sua análise é uma economia que se encontra inicialmente em estado-estacionário e que sofre um choque exógeno na forma de um aumento do investimento desejado pelos empresários. Inicialmente, esse acréscimo no investimento desejado vai produzir um aumento da demanda por finance, a qual, via de regra, será atendida por um aumento do crédito bancário de curto prazo. A implementação dos novos projetos de investimento vai detonar o processo do multiplicador Keynesiano, gerando, ao final dele, um acréscimo do nível de renda e, conseqüentemente, do nível de poupança. Supondo uma economia fechada e sem atividades fiscais, o acréscimo observado no nível de poupança será suficiente para fazer o funding das dívidas de curto prazo em obrigações de longo prazo. Mais especificamente, a poupança das famílias terá crescido numa magnitude suficiente para que essas possam comprar títulos e ações emitidos pelas empresas com o intuito de transformar as suas dívidas de curto prazo junto aos bancos comerciais em dívida de longo prazo junto às famílias.

No entanto, a preferência pela liquidez das famílias fará com que uma parte dessa poupança seja utilizada para a aquisição de saldos monetários. Dessa forma, a demanda por títulos e ações ao nível inicial de preços e taxa de juros será inferior às novas colocações no mercado de capitais, criando assim uma pressão baixista sobre os preços desses papéis, produzindo, portanto, um aumento da taxa de juros de longo prazo. Se esse aumento for suficientemente grande, poderá desestimular novos acréscimos do nível de investimento, interrompendo assim o processo de crescimento econômico. Para evitar que um acréscimo da taxa de juros de longo prazo aborte o crescimento da economia, a política monetária deve ser utilizada com um elevado grau de flexibilidade, permitindo, por exemplo, que o Banco Central possa realizar intervenções no mercado de capitais na forma de operações de compra de títulos privados de longo prazo com o intuito de sustentar os preços desses papéis.

Daqui se segue, portanto, que a política monetária não deve ser conduzida com base em regras muito rígidas que limitem o grau de autonomia com a qual o Banco Central pode engendrar variações na oferta de moeda e, por conseguinte, na taxa de juros de curto prazo. Uma rigidez excessiva na condução da política monetária, na forma de limites preestabelecidos à expansão dos agregados monetários, ou a adesão estrita a 
uma meta inflacionária, sem levar em conta os requerimentos de liquidez para o crescimento de longo prazo, podem impactar negativamente na taxa de juros de longo prazo (ou seja, a taxa de retorno dos papéis comercializados no mercado de capitais), à medida que aumentos não antecipados na preferência pela liquidez não sejam atendidos por um aumento da oferta de moeda. Dado que aumentos na taxa de juros de longo prazo desestimulam a acumulação de capital, segue-se que o crescimento pode ser afetado negativamente por uma política monetária conduzida de forma excessivamente rígida. Por conseguinte, um regime monetário mais flexível pode, dentro de certos limites, ${ }^{9}$ atuar de forma favorável ao crescimento econômico de longo prazo.

Com base nessas idéias, a especificação empírica do modelo de crescimento adotado é "mista" e "eclética": tem um núcleo convencional, baseado na literatura empírica de crescimento, ao qual se adicionam variáveis que buscam descrever a flexibilidade restrita da política monetária na experiência internacional, no que se refere ao arranjo institucional do regime de IT. A escolha das variáveis se baseou no critério de escolha daquelas que poderiam servir de parâmetro para descrever um regime de IT como "apertado" ou "flexível" - dado o papel que a flexibilidade do regime tem sobre a taxa de juros de longo prazo, de acordo com a apontada relação dos requerimentos de liquidez com o crescimento da economia no longo prazo, estilizados no modelo de Davidson (1968).

\section{4_Análise econométrica}

Uma ampla inspeção das experiências dos diversos países e das características particulares de seus regimes de IT torna possível estabelecer a existência de alguns padrões típicos de formatação institucional dos arcabouços existentes e dos resultados que cada desenho proporcionou a cada país. No entanto, inspeções visuais ou históricas apenas sugerem interpretações plausíveis, sem permitir qualquer inferência estatisticamente significante. Esta seção busca saber como determinadas características institucionais associadas às adoções de regimes de IT têm impactado o desempenho do produto real nos últimos anos usando econometria, com dados da experiência acumulada dos diversos países.

A estrutura de análise de painel tem seus méritos particulares em contraposição às regressões cross-country convencionais, em que só se pode mensurar ou determinar aqueles fatores que são tangíveis o suficiente para se instituir uma medida de indicadores que sejam internacionalmente com-

\footnotetext{
Essa afirmação não deve ser vista como apologia ao "inflacionismo". Com efeito, a literatura teórica e empírica sobre inflação e crescimento mostram que, a partir de um certo ponto, aumentos da taxa de inflação têm um claro efeito negativo sobre o crescimento de longo prazo. Isso acontece porque a instabilidade do nível geral de preços causada pela inflação tende a produzir mudanças na alocação de recursos entre os diferentes setores da economia, resultando, em geral, numa redução da eficiência e do bem-estar dos agentes econômicos. A esse respeito, ver Woodford (2003, p. 5).
} 
paráveis. Entretanto, como sublinhado em Nelson (1998), fatores intangíveis, tais como a organização e as instituições - dimensões da interação social que não podem ser diretamente observados ou medidos - também têm impactos no caminho do crescimento da economia. Levando-se em conta os efeitos individuais de um país em consideração, o instrumental do painel econométrico permite o controle da heterogeneidade desses fatores específicos dos países que não são observáveis, e os quais se podem razoavelmente assumir permanecerem constantes dentro do período em investigação (Peneder, 2004).

Há uma literatura bastante ampla a respeito da estimação de modelos de crescimento do produto. Embora não exista um único modelo ao qual todos os analistas subscrevam como o ideal, existe amplo consenso sobre qual seria o "esqueleto" de um modelo de crescimento: seguindo os trabalhos de Levine e Renelt (1992) e Salai-Martin (1997), há certa convergência sobre quais são as variáveis a ser incluídas nos modelos empíricos de crescimento. Muitas das variáveis convencionais são: a taxa de investimento como proporção do PIB, o crescimento populacional, o capital humano, etc. A especificação utilizada para o propósito deste trabalho expande essa análise, incluindo variáveis que caracterizem a flexi- bilidade do arranjo institucional do regime de metas dos países selecionados, quais sejam, aqueles que formalmente adotaram o regime de IT. A especificação básica do modelo é:

$$
\begin{aligned}
\Delta y_{i, t} & =\beta_{1} \Delta y_{i, t-1}+\beta_{2} \Delta y_{i, t-2}+\alpha_{1} \Delta P O P_{i, t}+ \\
& +\alpha_{2} \Delta P O P_{i, t-1}+\alpha_{3} \Delta G D I_{i, t}+ \\
& +\alpha_{4} \Delta G D I_{i, t-1}+\psi+\Delta \varepsilon_{i, t}
\end{aligned}
$$

onde: $\Delta y_{i, t}$ é a taxa de crescimento do PIB per capita, com 2000 como ano-base;

$\Delta y_{i, t-1}$ é a taxa de crescimento do PIB per capita defasada em um período;

$\Delta y_{i, t-2}$ é a taxa de crescimento do PIB per capita defasada em dois períodos;

$\triangle P O P_{i, t}$ é a taxa de crescimento da população;

$\triangle P O P_{i, t-1}$ é a taxa de crescimento da população defasada em um período;

$\Delta G D I_{i, t}$ é a participação percentual do investimento no PIB;

$\Delta G D I_{i, t-1}$ é a participação percentual do investimento no PIB defasada em um período; 
$\psi$ é um conjunto de variáveis dummy que tratam da adoção ou mudança do arranjo IT.

O modelo de crescimento é especificado dinamicamente, portanto, com a introdução de uma variável dependente defasada em dois períodos. O uso de um modelo dinâmico tem a vantagem de permitir que as mudanças nos regimes de IT, captadas pelas variáveis categóricas, tenham impacto no crescimento tanto no curto como no longo prazo.

Entretanto, a inclusão das variáveis defasadas induz a uma correlação entre o termo erro e a variável dependente defasada. Existem várias técnicas para lidar com esse problema na especificação: o método do estimador generalizado de momentos (GMM) de Arellano-Bond (1991) é amplamente utilizado em modelos de painéis dinâmicos com períodos curtos, tornando-o adequado à investigação a que se propõe este trabalho, sendo, portanto, a técnica de estimação utilizada. Arellano-Bond (1991) resolvem o problema da correlação entre a variável dependente diferenciada e o erro transformado com a utilização de uma extensa matriz de variáveis instrumentais.

Os regressores podem ser divididos em dois grupos de explicação estrutural do crescimento do produto. O primeiro, seguindo Peneder (2004), é o de variáveis de nível macro, que, juntas, compõem a especificação base, no qual nenhuma variável de caráter institucional do arranjo monetário é incluída; em (1), essas variáveis são crescimento da população $\left(\triangle P O P_{i, t}\right)$ e o crescimento da parcela do PIB em investimento $\left(\Delta G D I_{i, t}\right)$. Além dessas variáveis, foram incluídas dummies para os anos individuais (uma para cada ano, do período de 1991 a 2004) como forma de captar a ampla tendência internacional do ciclo de negócios na trajetória de crescimento dos países.

O segundo grupo de variáveis são dummies, representadas em (1) por $\psi$, escolhidas para servirem de proxy da flexibilidade do arcabouço institucional monetário do regime de IT. As variáveis são: "Core Infla- tion Target", "Adoção de Horizonte de um Ano" e "Desvio da Meta". ${ }^{10}$ Seguin-

$\begin{array}{ll}\text { 10 Todas as variáveis categóricas } & \text { um ano para convergência da } \\ \text { foram adiantadas em um perío- } & \text { meta determinam uma } \\ \text { do, como forma aproximada de } & \text { configuração de resposta } \\ \text { captar a conhecida defasagem } & \text { rígida na orientação da } \\ \text { dos efeitos monetários sobre o } & \text { política monetária. Por fim, a } \\ \text { comportamento do produto. } & \text { variável "Desvio da Meta" } \\ \text { As variáveis "Core Inflation”e } & \text { pode relacionar o resultado } \\ \text { "Adoção de Horizonte de } & \text { da perda da meta - possivel- } \\ \text { um Ano" relacionam-se } & \text { mente originada de metas } \\ \text { diretamente com a flexibilidade } & \text { ambiciosas demais ou prazos } \\ \text { do regime: aqueles que adotam a } & \begin{array}{l}\text { curtos de convergência deri- } \\ \text { inflação de núcleo reagem }\end{array} \\ \text { menos a impactos de preços } & \text { "apertada" - aos resultados } \\ \text { voláteis; ademais, aqueles que } & \text { em termos de crescimento } \\ \text { adotam o regime mais curto de } & \text { do produto dos países. }\end{array}$


11 Evidentemente "flexibilidade discricionária", dentro dos limites inerentes a um regime preocupado com a inflação.

12 Os países selecionados foram aqueles que adotaram oficialmente o regime IT, sendo os 23 seguintes que compõem a amostra utilizada no painel: Austrália, Chile, Canadá, Israel, Grã-Bretanha, Suécia, Espanha, México, República Tcheca, África do Sul, Tailândia, Islândia, Hungria, Noruega, Peru, Filipinas, Turquia, Coréia do Sul, Brasil, Colômbia, Polônia, Finlândia, Nova Zelândia.

13 Foram separados aqueles países que adotaram o IT num contexto de inflação moderadamente alta e por isso estabeleceram trajetórias declinantes para a meta, em distinção aos países que adotaram IT já com baixas taxas de inflação. do a estabelecida relação positiva entre flexibilidade adequada da política monetária e crescimento de longo prazo apontada por Davidson (1968), essas variáveis procuram caracterizar no arcabouço institucional dos regimes de metas, de forma aproximada, o grau de liberdade que a autoridade monetária tem para se adaptar aos choques da economia e prover a liquidez necessária para que não se prejudique o crescimento de longo prazo. De acordo com essa intuição, aquela formatação de regimes que permita maior grau de flexibilidade da política monetária ${ }^{11}$ terá impacto positivo sobre o desempenho de crescimento dos países.

Os dados foram coletados para 23 países $^{12}$ que oficialmente adotam o regime IT da amostra World Penn Table 6.2, construída por Heston, Summers em 2006. A amostra utilizada é um painel com séries temporais de 1991 a 2004, que cobre boa parte do período em que se oficializaram adoções de Bancos Centrais ao redor do mundo ao regime IT.

As estimações para o nível agregado de renda per capita estão na Tabela 1 . O teste de Sargan é satisfeito para todas as especificações, o teste para correlação de segunda ordem igualmente atende às condições de consistência sendo rejeitado. Para as várias especificações, é encontrado que a maioria das variáveis core tem seu sinal esperado e é sig- nificativa. A especificação básica (I) exclui todas as variáveis da categoria institucional monetária e é consistente com as expectativas a priori da literatura do crescimento.

A renda per capita, ceteris paribus, deve se reduzir com o aumento na taxa de crescimento da população: no modelo, embora a taxa para o período não seja significante, o coeficiente para a variável defasada é negativa e estatisticamente significante, como esperado. Os coeficientes para o investimento bruto em capital físico aparecem positivos para o período e para a variável defasada apenas nas especificações (I) e (II): para a especificação (I), a variável significativa é a do período, apenas; na especificação (II), a variável é significativa apenas quando defasada.

$\mathrm{Na}$ especificação (II) foi introduzida a variável categórica "Adoção do Inflation Targeting", que busca inferir se a formalização do regime IT pelos países tem alguma correlação positiva com as taxas de crescimento destes após a implementação. Os resultados não se mostram significativos a um nível de 10\% de significância. Deve ser sublinhado que uma série de tentativas de agrupamento dos países e segregação ${ }^{13}$ da amostra foi realizada para encontrar uma possível relação estatisticamente significante para essa variável. 
Tabela 1_ Regressões de painel dinâmico para o período de 1991-2004 do crescimento da renda "per capita" de países com regime IT

\begin{tabular}{|c|c|c|c|}
\hline Variável de independente $\quad \triangle G P D$ & (I) & (II) & (III) \\
\hline$\Delta y_{t-1}$ & $\begin{array}{l}0.4030 \\
(8.32)^{(b)}\end{array}$ & $\begin{array}{l}0.4000 \\
(8.23)^{(b)}\end{array}$ & $\begin{array}{c}0.3310 \\
(4.94)^{(b)}\end{array}$ \\
\hline$\Delta y_{t-2}$ & $\begin{array}{l}0.1930 \\
(3.58)^{(b)}\end{array}$ & $\begin{array}{l}0.1980 \\
(3.66)^{(b)}\end{array}$ & $\begin{array}{l}0.3000 \\
(3.93)^{(b)}\end{array}$ \\
\hline$\triangle P O P$ & $\begin{array}{l}0.5120 \\
(-0.11)\end{array}$ & $\begin{array}{c}-0.5310 \\
(-0.11)\end{array}$ & $\begin{array}{r}2.8650 \\
-0.2700\end{array}$ \\
\hline$\triangle P O P_{-1}$ & $\begin{array}{c}-5.4960 \\
(12.55)^{(\mathrm{b})}\end{array}$ & $\begin{array}{c}-5.5730 \\
(12.53)^{(b)}\end{array}$ & $\begin{array}{l}-6.2560 \\
(9.24)^{(b)}\end{array}$ \\
\hline$\Delta G D I$ & $\begin{array}{c}0.1300 \\
(-1.5)\end{array}$ & $\begin{array}{l}0.1500 \\
(-1.69)^{(\mathrm{c})}\end{array}$ & $\begin{array}{l}0.0210 \\
(-0.08)\end{array}$ \\
\hline$\Delta G D I_{-1}$ & $\begin{array}{l}0.0270 \\
(-0.38)\end{array}$ & $\begin{array}{c}0.0370 \\
(-0.5)\end{array}$ & $\begin{array}{l}-0.0580 \\
(-0.3)\end{array}$ \\
\hline Adoção do inflation targeting & $\begin{array}{l}\cdots \\
\cdots\end{array}$ & $\begin{array}{c}-0.0340 \\
(-1.03)\end{array}$ & $\begin{array}{l}\cdots \\
\cdots\end{array}$ \\
\hline Core inflation target & $\begin{array}{l}\ldots \\
\ldots\end{array}$ & $\begin{array}{l}\ldots \\
\ldots\end{array}$ & $\begin{array}{l}-0.2590 \\
(3.04)^{(b)}\end{array}$ \\
\hline Adoção de horizonte de um ano & $\begin{array}{l}\ldots \\
\ldots\end{array}$ & $\begin{array}{l}\ldots \\
\ldots\end{array}$ & $\begin{array}{l}-0.0900 \\
(-1.89)^{(\mathrm{c})}\end{array}$ \\
\hline Desvio da meta (anos) & $\begin{array}{l}\ldots \\
\ldots\end{array}$ & $\begin{array}{l}\ldots \\
\ldots\end{array}$ & $\begin{array}{l}-0.3690 \\
(3.91)^{(b)}\end{array}$ \\
\hline Year dummies & Sim & Sim & Sim \\
\hline Constante & $\begin{array}{c}-0.0190 \\
(-1.03)\end{array}$ & $\begin{array}{l}0.0020 \\
(-0.57)\end{array}$ & $\begin{array}{c}-0.0120 \\
(-1.22)\end{array}$ \\
\hline Observações & 247 & 247 & 120 \\
\hline Número de países da amostra & 23 & 23 & 22 \\
\hline Wald chi ${ }^{2}$ & 463.95 & 464.19 & 334.07 \\
\hline Sargan test of over-identifying restrictions $\left(\mathrm{chi}^{2}\right)$ & 213.38 & 211.98 & 101.63 \\
\hline $\begin{array}{l}\text { Arellano-Bond test that average autocovariance } \\
\text { in residuals of order } 1 \text { is } 0\end{array}$ & -9.82 & -9.74 & -5.04 \\
\hline $\begin{array}{l}\text { Arellano-Bond test that average autocovariance } \\
\text { in residuals of order } 2 \text { is } 0\end{array}$ & 3.13 & 3.02 & -0.78 \\
\hline
\end{tabular}

(a) significativo a $5 \%$; (b) significativo a $1 \%$; (c) significativo a $10 \%$.

Fonte: Resultado: cálculo dos autores.

A amostra reduzida resultante (muitos países adotaram apenas recentemente o IT) e os inevitáveis missing values, no entan- to, inviabilizaram a estabilidade do modelo econométrico para essas experiências. Assim, de acordo com os resultados, não há re- 
$\ldots \ldots \ldots \ldots$

14 Evidentemente, o curto período de experiência de muitos países (e os períodos diferentes de adoção) dificulta uma conclusão decisiva a respeito da significância estatística dessa variável. lação estatisticamente significante entre adoção de um sistema de metas de inflação e melhora na performance da trajetória de produto dos países. ${ }^{14}$ A especificação (III) inclui três variáveis categóricas: "Core Inflation Target", "Adoção de horizonte de um ano" e "Desvio da meta". Como foi visto extensivamente neste trabalho, boa parte do espaço que os Bancos Centrais têm para desenhar seu regime de metas de inflação como "apertado" ou "flexível" pode, de maneira simplificada, resumir-se na forma em que escolhem formatar esses três itens.

É importante notar que, como para os diversos países existiram períodos diferentes de adoção (e abandono) das metas inflacionárias, essas variáveis detêm vários missing values, uma vez que, no período em que um país não tinha adotado o regime IT, a dummy em consideração não é determinada.

Os coeficientes são negativos e estatisticamente significativos para as três variáveis categóricas na especificação (III). O sinal negativo para a variável que descreve a adoção de índices core para as metas sugere que a maior credibilidade do uso de índices cheios supera a potencial menor volatilidade da adoção do core que poderia prejudicar o desempenho do produto. Em geral, o principal argumento contra o uso de core inflation é de que o índice é menos representativo da perda total de poder de com- pra do dinheiro; os agentes estão preocupados com toda a cesta de consumo. No caso do Brasil, por exemplo, a exclusão dos itens com preços administrados pelo governo implicaria deixar de fora $30 \%$ da cesta de consumo representativa (Minella et al., 2002). Assim sendo, há motivação para os agentes questionarem uma política monetária que não se preocupa com o índice de preços amplo, e a perda de credibilidade decorrente poderia fazer com que a autoridade monetária tivesse maior dificuldade em reduzir expectativas inflacionárias e acomodar choques exógenos, que, por fim, determinariam um resultado negativo na trajetória de crescimento dos países que adotam o índice core como referência para as metas.

O sinal negativo para a variável "horizonte de um ano" sugere que a adoção por alguns países de um termo tão curto para a convergência à meta - regimes mais apertados, buscando consolidação - paga um custo em termos do seu desempenho no crescimento econômico.

A variável "desvio da meta" também aparece com sinal negativo. Uma explicação provável para esse resultado é que a perda da meta seja um sinal negativo para a credibilidade da política monetária, e que as autoridades necessitem instrumentalizar em resposta políticas de correção subseqüentes drásticas que são nocivas ao cresci- 
mento. Cabe notar que um horizonte de convergência curto potencializa a possibilidade de o Banco Central não atingir a meta, podendo ser um dos canais pelo qual o horizonte de prazo de um ano seja um fator determinante negativo à performance econômica dos países. ${ }^{15}$

O Gráfico 1 mostra a experiência recente do Brasil com relação à inflação antes e depois da adoção de metas e a relação entre metas fixadas e inflação efetiva.

No gráfico percebe-se que a taxa média de inflação antes da adoção não é significativamente diferente da taxa média observada após o regime de metas.

Entretanto, para o objetivo da análise aqui feita, vale ressaltar que, até 2002, o intervalo de tolerância da inflação em torno do centro da meta era de 2 pontos percentuais e que, após 2002, foi de 2,5 pontos percentuais. Enquanto nos dois primeiros anos as metas foram cumpridas pelo Banco Central (considerando a banda permitida), nos dois anos seguintes a inflação observada foi amplamente superior às metas estabelecidas. Como foi visto, a experiência internacional generalizada no painel mostra que os desvios da meta e o horizonte curto de busca à convergência são nocivos ao crescimento, e o atual arranjo do IT no Brasil pode estar incorrendo justamente em falhas que não só minam a credibilidade do regime, mas têm custos consideráveis na trajetória de crescimento. ${ }^{16}$

$\begin{array}{llll}15 \text { Aqui cabe uma observação } & \text { A argumentação defendida ao } & \text { apenas como mais um } \\ \text { importante. A argumentação } & \text { longo do trabalho é que } & \text { potencial veículo prejudicial } \\ \text { deste trabalho não se } & \text { a perda de flexibilidade na } & \text { à performance de } \\ \text { baseia simplesmente na idéia de } & \text { condução da política } & \text { produto dos países, podendo } \\ \text { que um regime de IT mais } & \text { monetária, em função de um } & \text { (ou não) estar relacionado à } \\ \text { apertado pode levar à perda das } & \text { arcabouço institucional muito } & \text { rigidez do regime IT. } \\ \text { metas e, dessa forma, à perda } & \text { rígido, tem efeitos diretos } & \text { 16 Obviamente, a perda das } \\ \text { de credibilidade por parte da } & \text { nocivos ao crescimento de } & \text { metas tem motivos outros que } \\ \text { autoridade monetária e do } & \text { longo prazo, mesmo quando } & \text { não somente a formatação do } \\ \text { desempenho do produto de um } & \text { esse regime é bem-sucedido na } & \text { arranjo institucional do IT, } \\ \text { país. De fato, a experiência } & \text { obtenção das metas de inflação } & \text { como se poderia depreender } \\ \text { recente do regime de metas no } & \text { preestabelecidas. A perda de } & \text { rapidamente desta análise: em } \\ \text { Brasil mostra que um regime } & \text { metas pode ter motivos outros } & \text { 2001, o país enfrentou um } \\ \text { de IT rígido pode ser } & \text { que não a simples rigidez da } & \text { choque de preços causado pelo } \\ \text { bem-sucedido no que se refere } & \text { política monetária, como apon- } & \text { racionamento de energia e pela } \\ \text { à obtenção das metas (desde } & \text { tado adiante no texto, para o } & \text { volatilidade cambial detonada } \\ \begin{array}{l}\text { 2004 o BCB tem tido sucesso } \\ \text { na obtenção dessas). }\end{array} & \begin{array}{l}\text { caso do Brasil. O sinal negativo } \\ \text { da perda das metas aparece }\end{array} & \begin{array}{l}\text { pela crise da Argentina e } \\ \text { conseqüente maior aversão ao }\end{array}\end{array}$
risco no mercado de capitais Em 2002, a depreciação cambial, gerada pelas incertezas inerentes ao período eleitoral, provocou elevado choque de preços. Entretanto, o arranjo do regime IT com prazos estreitos reforça a probabilidade de perda das metas e tem custo social elevado na medida em que, como foi visto no painel, a existência dos desvios

e a manutenção de horizontes temporais estreitos podem reduzir o desempenho de crescimento do produto. 


\section{Gráfico 1_Comportamento da inflação antes e depois da adoção do regime de metas}

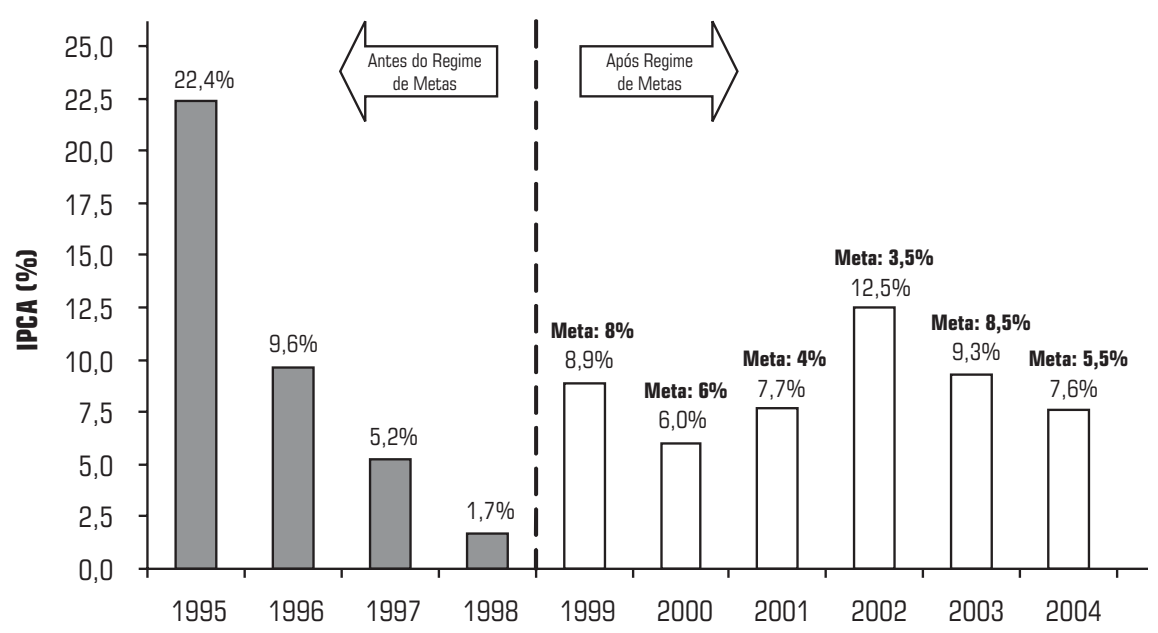

Fonte: IBGE e Banco Central. Elaboração: FIESP.

Em Minella et al. (2002), discute-se que, apesar de a inflação estar acima do limite superior do intervalo de tolerância desde meados de 2001, isso não quer dizer que o regime IT não tenha tido sucesso em controlar a inflação no Brasil: para os autores, esses resultados não são argumentos suficientes para avaliar o desempenho do Banco Central. Devem ser consideradas as expectativas inflacionárias e os choques em que a economia incorreu no período para avaliar a credibilidade e a eficiência do Banco Central. Esse argumento, entretanto, não seria contrário à constatação de que um regime de IT mais "flexível", na medida em que permita maior folga na obtenção da meta e, por isso mesmo, evite perda de metas, seja uma estrutura que invoque maior credibilidade à autoridade monetária e que permita a acomodação dos choques de forma mais suave, não necessitando assim do uso freqüente dos instrumentos para comunicar credibilidade ao público e que acabe sendo prejudicial à performance do produto.

Uma alternativa a aceitar desvios temporários em relação à meta pode ser a de utilizar um horizonte de convergência de períodos mais longos. Uma menor volatilidade no target da inflação, teoricamente, gera menor necessidade de reação do governo e, portanto, menor volatilidade do produto e emprego. Mas esse não é um 
problema de solução fácil: por exemplo, Giambiagi e Carvalho (1999), analisando o caso de o BC utilizar a média de dois anos, argumenta que a variância desse novo target tende a ser menor e, portanto, que o Banco Central poderá ter reações menos bruscas. Entretanto, o trabalho chama a atenção para o fato de que a adoção de médias mais longas é mais vantajosa quando a inflação não tiver um caráter inercial. Nesse caso, os choques de preços tendem a não se perpetuar no sistema. Quando a covariância das inflações é positiva, entretanto, nem sempre é benéfico usar médias mais longas. Nesse caso os choques tendem a se perpetuar: adiar o combate à inflação logo no primeiro ano acaba gerando maior problema no futuro. Existe um intervalo em que, a despeito da covariância positiva entre as inflações, vale a pena adotar médias mais longas. Para níveis mais baixos de inflação, quando a inércia inflacionária tende a ser pequena, $\mathrm{o}$ autor sugere que o $\mathrm{BC}$ pode usar target médias mais longas de inflação; para taxas de inflação abaixo de $4 \%$, o BC pode utilizar uma média de 2 anos. Ou seja: a flexibilização viria com a consolidação paulatina do regime IT como framework monetário no país.

Outra alternativa aponta para o aumento das bandas das metas inflacionárias, de forma a evitar os desvios. A largura das bandas deve ser ampla o suficiente para permitir que as taxas de inflação permaneçam dentro delas na maioria das circunstâncias, mas ao mesmo tempo não devem ser largas demais, evitando-se assim uma conduta "frouxa" da política monetária e, portanto, pouco crível. O aumento das bandas até um limite razoável pode significar o aumento da flexibilidade suficiente para que as metas sejam atingidas com maior constância, derivando assim maior credibilidade à autoridade monetária. $\mathrm{O}$ tamanho das bandas deve ser estabelecido de acordo com três fatores: depende do limite determinado pelos modelos de previsão do Banco Central, da freqüência e magnitude dos choques aos quais a economia está sujeita, e da duração da defasagem dos efeitos da política monetária (Minella et al., 2002).

\section{5_Considerações finais}

A disseminação do regime de metas monetárias nos anos 1990 e o sucesso da maioria dos países que adotaram o novo framework monetário em manter baixos níveis de taxas de inflação geraram vasta literatura, que estabelece certo consenso quanto às virtudes do regime no combate à inflação e à consolidação da credibilidade. Foi visto que a adoção do regime IT pode se dar com desenhos institucionais diversos, intrinsecamente associados ao trade-off en- 
tre flexibilidade e credibilidade com que se defrontam os Bancos Centrais que adotam o IT. Esse trade-off dá origem a regimes IT "flexíveis" ou "apertados", de acordo com a ênfase que a autoridade monetária dá à flexibilidade ou à credibilidade quando estrutura os instrumentos e o arranjo institucional para a persecução de metas.

Este trabalho buscou avaliar o papel do desenho institucional como responsável pelo desempenho em termos de crescimento econômico dos países que adotaram o IT. Nesse sentido, os resultados apóiam a hipótese de que a adoção do IPC cheio, a utilização de um horizonte de convergência para as metas maior do que o de um ano, e a capacidade de os Bancos Centrais evitarem desvios das metas são fatores benéficos para a trajetória de crescimento do produto.

Os resultados, as argumentações e as considerações vistas podem dar sustentação à hipótese de que, uma vez consolidado o regime de metas de inflação no país e pagos os custos em termos de crescimento do produto de uma política IT "apertada", o Banco Central possa flexibilizar seu desenho institucional - em especial, alargando o prazo de convergência da inflação às metas ou aumentando as bandas - como forma de preservar a performance do crescimento econômico do país. 


\section{Referências bibliográficas}

AKERLOF, G.; DICKENS, W.; PERRY, G. The macroeconomics of low inflation. Brookings Papers on Economic Activity, n. 1, 1996.

ARELLANO, Manuel; BOND. S. Some test of specification for panel data: Monte Carlo evidence and an application to employment equations. Review of Economic Studies, n. 58, 1991.

BALL, L.; SHERIDAN, N. Does inflation targeting matter? National Burean of Economic Research, 2003. (Working Paper, n. 9577).

BERNANKE, B.; LAUBACH, T.; MISHKIN, F.; POSEN, A. Inflation targeting. Princeton, NJ: Princeton University Press, 1999.

CARLIN, W.; SOSKICE, D. Macroeconomics: imperfections, institutions, and policies. Oxford Press, 2006.

CARVALHO, F. J. C. et al. Economia monetária e financeira: teoria e política. Campus: Rio de Janeiro, 2000.

CECCHETTI, S.; EHRMANN, M. Does inflation targeting increase output volatility? An international comparison of policymakers' preferences and outcomes. Central Bank of Chile, 2000. (Working Papers, n. 69).
COLETTI, D; SELODY, J.; WILKINS, C. Another look at the inflation-target horizon. Bank of Canada Review, 2006.

\section{DAVIDSON, P. Money,}

Portfolio balance, capital accumulation and economic growth. Econometrica, v. 367 , n. 2,1968

DAVIDSON, P. Post keynesian macroeconomic theory. Edward Elgar: Aldershot. 1994.

FEDERAÇÃO DAS INDÚSTRIAS DO ESTADO DE SÃO PAULO. Nota sobre o regime de metas de inflação no Brasil. Disponível em: <http://www. fiesp.com.br/download/ pesquisa/regime_metas_inflaçao. pdf.> Acesso em: jan. 2007.

FELDSTEIN, M. Capital income taxes and the benefits of price stability. 1997. (NBER Working Paper, n. 6200).

FERREIRA, T.; PETRASSI, M. Regime de metas para a inflação: resenha sobre a experiência internacional. Banco Central do Brasil, 2002. Mimeo.

FRIEDMAN, M. The role of monetary policy. American Economic Review, mar. 1968.
GIAMBIAGI, F.; CARVALHO, J. As metas de inflação: sugestões para um regime permanente. Rio de Janeiro, BNDES n. 25, 2001.

HESTON, A.; SUMMERS, R.; ATEN, B. Penn World Table Version 6.2. Center for International Comparisons of Production, Income and Prices at the University of Pennsylvania, September 2006.

KYDLAND, F.; PRESCOT'T, E. Rules rather than discretion: the inconsistency of optimal plans. Journal of Political Economy, v. 85, 1977.

\section{LEVINE, R.; RENELT, P. A} sensitivity analysis of cross-country growth regressions. American Economic Review, n. 82, 1992.

MINELLA, A.; FREITAS, P.; GOLFAJN, I.; MUINHOS, M. Inflation targeting in Brazil: lessons and challenges. 2002. (BIS Papers, n. 19)

MISHKIN, F. Issues in inflation targeting. Price stability and the long-run target for monetary policy. Bank of Canada: Ottawa, Canada , 2001.
MISHKIN, F. Inflation targeting in emerging market countries. 2000. (NBER Working Paper Series, n. 7618),

MISHKIN, F.; POSEN, Inflation targeting: lessons from four countries. Economic Policy Review, Federal Reserve Bank of New York, 1997.

NELSON, R. The agenda for growth theory: a different point of view. Cambridge Journal of Economics, n. 22, 1998.

PENEDER, M. Tracing empirical trails of schumpeterian development. Papers on Economics and Evolution, n. 409, 2004.

POOLE, W. Is inflation too low? Federal Reserve Bank of St. Louis Review, n. 81, 1999.

SALA-i-MARTIN, X. I just ran two million regressions. American Economic Review, n. 87, 1997.

SICSU, J. Teoria e evidências do regime de metas inflacionárias. Revista de Economia Politica, v. 22, 2002.

SIDRAUSKI, M. Inflation and economic growth. American Economic Review, v. 57, n. 2, 1967. TOBIN, J. Money and economic growth. Econometrica, n. 4, 1965. 
WALSH, C. Monetary theory and policy. MIT Press: Cambridge (Mass.), 2001.

WOODFORD, M. Interest and prices: foundations of a theory of monetary policy. Princeton

University Press: Princeton, 2003.

WU, T. Does inflation targeting reduce inflation? An analysis for the OECD industrial countries.

Working Paper Series, Banco

Central do Brasil, n. 83, 2004.

E-mail de contato dos autores: - sir.mrocha@gmail.com

- joreiro@ufpr.br

Artigo recebido em maio de 2007;

aprovado em fevereiro de 2008. 